\title{
Radiation-Induced Breast Angiosacoma: A Case Report
}

\author{
A. Arfa $^{1 *}$, D. Van Gestel ${ }^{2}$, A. Benider ${ }^{2}$
}

${ }_{1}^{1}$ Departement of Radiation Oncology, Institute Jules Bordet, Boulevard de Waterloo 121, 1000 Bruxelles, Belgium
${ }^{2}$ Professor, Department of Radiation Oncology, Chu ibn Rochd Pavillon 40, Casablanca, Morocco

DOI: $10.36347 /$ sjmcr.2020.v08i07.012

| Received: 15.07.2020 | Accepted: 23.07.2020 | Published: 24.07.2020

*Corresponding author: A. Arfa

Abstract

Case Report

Breast angiosarcoma is a rare conjunctival tumor of vascular endothelial origin, primary in young patients, radioinduced in the elderly, characterized by its malignancy and by its polymorphic clinical and radiological presentation; it has a very poor prognosis, the frequent occurrence of visceral metastases and rapid recurrence. We report a case of breast angiosarcoma, in a 56 year old patient, with a history of breast cancer, treated by conservative surgery and adjuvant radiotherapy. We will discuss through this observation, the epidemiological, diagnostic and therapeutic aspects of this type of rare aggressive tumors.

Keywords: Angiosrcoma, breast, radio-induced, clinic, treatment.

Copyright @ 2020: This is an open-access article distributed under the terms of the Creative Commons Attribution license which permits unrestricted use, distribution, and reproduction in any medium for non-commercial use (NonCommercial, or CC-BY-NC) provided the original author and source are credited.

\section{INTRODUCTION}

The breast angiosarcoma is a rare connective malignancy of vascular origin. It occurs either spontaneously, with no obvious trigger for younger women (30-40), or after irradiation as part of conservative treatment for breast cancer for older women [1-6].

It is characterized by a strong malignancy of which the evolution is towards rapid recurrence and the appearance of visceral metastases. Its histological diagnosis is based on a rigorous analysis of the pieces of excision [7-10].

We report the observation of radiation-induced angiosarcoma in a 43-year-old patient who received conservative treatment for breast cancer 6 years ago.

We will discuss the epidemiological, diagnostic, therapeutic and progressive aspects of this type of tumor.

\section{ObServation}

Mme T. M, 68 years old, followed since November 2014 for IDC of the right breast cT2N1M0 luminal B, Fish amplified.
The patient received 8 standard neo-adjuvant chemotherapy courses (4 EC cycles then 4 Taxol cycles) associated with herceptin.

The patient benefited in April 2015 of a tumorectomy and an axillary recess then reconstruction by oncoplasty with pathology (stage ypT1bN0).

Then our patient had benefited from a local treatment based on adjuvant radiotherapy on the right breast and the right supraclavicular ganglion areas at a dose of $40.05 \mathrm{~Gy}$ according to a hypofractionated radiation with a boost of $15 \mathrm{~Gy}$ at the level of the tumor bed. Anti-aromatase hormone therapy was prescribed, due to the positivity of hormone receptors, for a period of 5 years.

Five years later the patient consulted for a rash on the level of the red hot breast beyond the inferointernal quadrant, the clinical examination found thick skin with free ganglionic areas. (Figure-1) The mammography had shown an increase in opacity, dense, homogeneous, large in size and with fuzzy limits, without microcalcifications. Ultrasound showed infiltration with thickening of the fatty tissue of the breast, without visible cystic or tumor formation, accompanied by frank. 


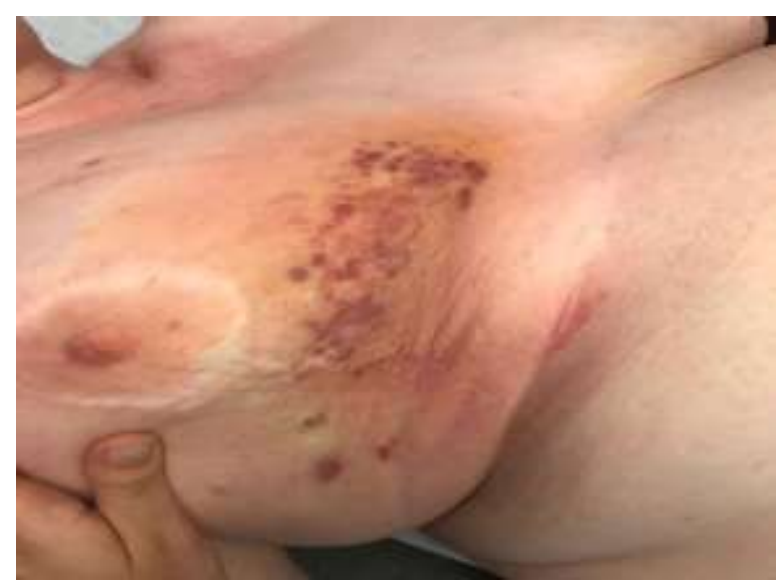

Fig-1: Red lesion in the infero-internal quadrant

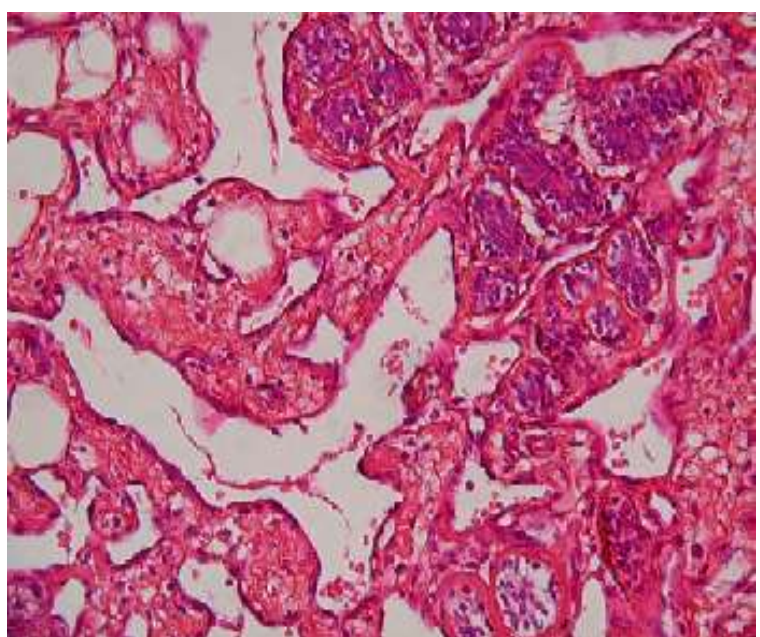

Fig-2: Histological aspect of a well-differentiated radio-induced angiosarcoma

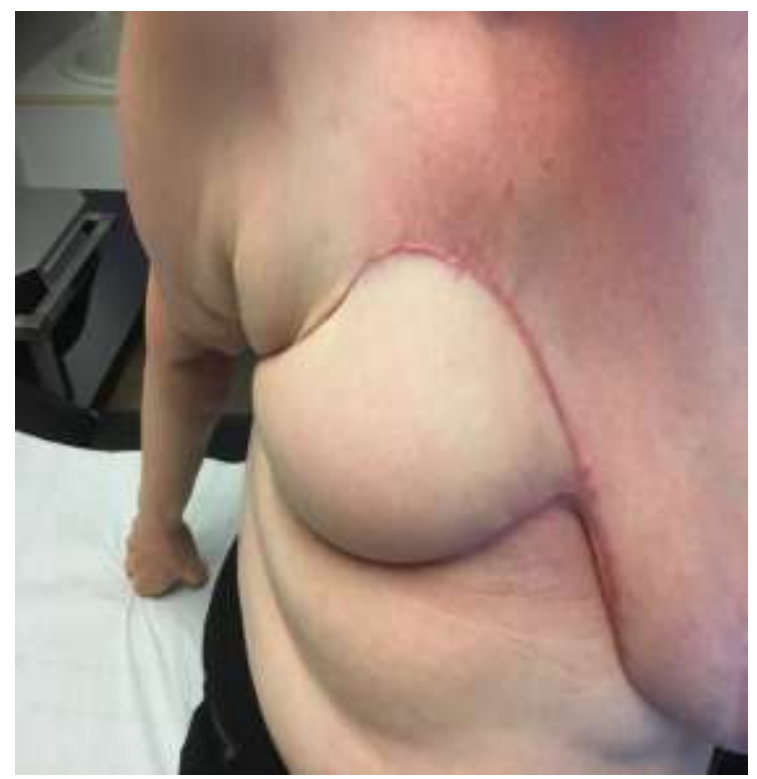

Fig-3: Purple nodule at the level of the upper bank of the mastectomy scar

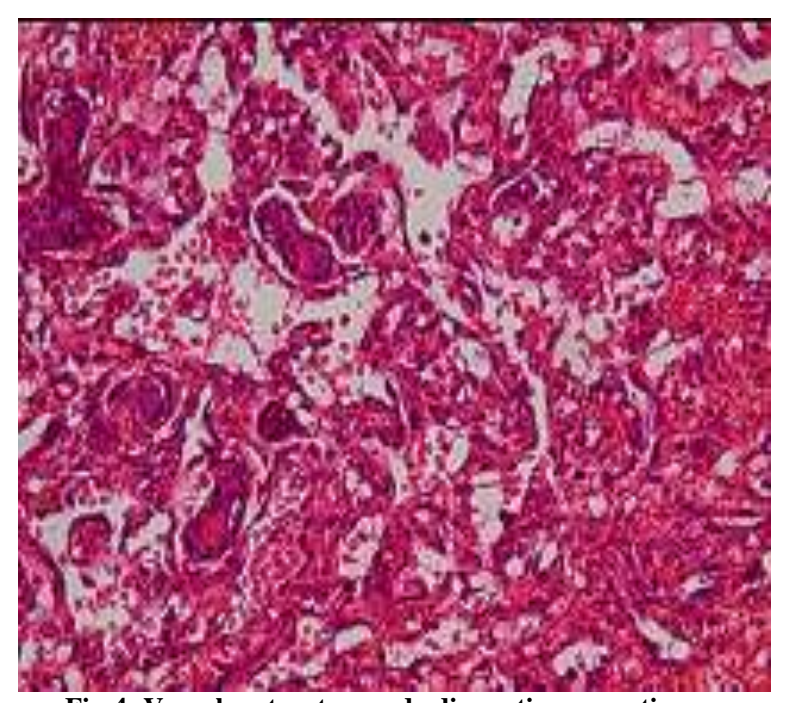

Fig-4: Vascular structers and adipose tissue creating an anastomotic network borded by cells with enlarged nuclei

\section{DISCUSSION}

Conservative treatment of breast cancer is a therapeutic option of choice thanks to the generalization of screening and early diagnosis of cancerous lesions.

Radiation therapy is a mandatory step in the conservative treatment of breast cancer, it is often indicated postoperatively. However, a cumulative dose greater than $40 \mathrm{~Gy}$, can induce the development of certain tumors such as angiosarcoma in the long term [1].

Angiosarcoma of the breast was also called hemangiosarcoma, hemangioendotheliosarcoma, hemangioblastoma, Angioblastoma, malignant hemangioendothelioma [2]. The first case was reported by Borman in 1907 [3].

It is a rare tumor representing $0.04 \%$ of All malignant breast tumors and 8 to $10 \%$ breast sarcomas.

It is a tumor that primarily affects young women during genital activity, especially between 30 and 40 years of age [4]. But, all age groups are concerned, from 13 to 85 years old

Several factors have been incriminated in the genesis of angiosarcomas [5]: exposure to arsenic, to chloroethene, for the hepatic forms; chronic endoluminal irritation by a foreign body for the digestive localizations; chronic lymphedema (StewartTreves syndrome) for limb angiomas; pre-existing radiotherapy explains the secondary forms.

The first case of secondary BAS after conservative radio-surgical treatment of breast cancer was reported in 1987 by Body et al., [6] and since then, a hundred new cases have been reported [7]. 
The radio-induced form occurs, especially, in the elderly woman, with a latency of 29 to 72 months [4], which is the case for our patient.

The incidence of BAS after radiotherapy for breast cancer is estimated between 0.05 and $0.2 \%$.

Cahan et al., proposed four criteria for the diagnosis of radio-induced sarcomas [8]:

- A history of radiotherapy;

- Clinical latency of several years (more than five years);

- The occurrence of sarcoma in the irradiated field;

- Histological confirmation of the sarcomatous nature of the post-radiation lesion.

Our observation met these diagnostic criteria

BAS is discovered in the majority of cases, following a nodule having a vascular, pulsating character, of black purplish color, bulky with a size often between 2 and $11 \mathrm{~cm}$ [11], which increases rapidly in size.

Two clinical signs are pathognomonic of angiosarcoma of the breast: the purplish appearance of the skin next to the tumor and the pulsatile character of the mass [12], which answers our observation.

Axillary lymphadenopathy is exceptional, it does not concern than highly evolved forms [13].

The diagnosis of BAS is essentially based on histological analysis of biopsies performed on a suspicious lesion $[9,10]$. Mammography and cytology are most often lacking in this context $[9,10]$. Surgery represents the standard treatment for radio-induced BAS [9, 14]. Wide surgical excision is necessary and healthy margins of 2 to $3 \mathrm{~cm}$ confirmed by pathology analysis are recommended [15]. This so-called excision surgery poses the problem of skin cover, hence the frequent use of muscle flaps and dermo-epidermal grafts F. Leung et al., [16]. Finally, given the hematogenous spread of these tumors, lymphadenectomy is not indicated [14]

At the end of these histological criteria, two histological classifications were proposed by Donnel [17], and by Merino [18].

Each of these classifications includes three histological types containing the same items; the most currently used is that of Donnell. For tumors difficult to identify on the microscopic study, the vascular nature of the lesion can be confirmed by the immunohistochemical study.

The endothelial markers CD31, CD34, factor VIII, Ulex europaeus agglutinin 1 and vascular endothelial growth factor (VEGF) are typically expressed by angiosarcoma. Only the expression of CD 31 is specific to the latter [5].

The prognosis depends on the histological grade, with a 10-year survival for all forms (primary or secondary) at $76 \%$ for well-differentiated or grade 1 forms, $20 \%$ for grade 3 or poorly differentiated.

The place of adjuvant treatments remains limited in the treatment of post-radiation BAS. To date, neither radiotherapy nor chemotherapy has proven effective $[14,12]$.

The natural course of radiation-induced angiosarcoma is more or less rapid towards death, which occurs in a metastatic spread after a median survival of 24 months [4].

Tumor size at diagnosis is the major prognostic factor, hence the importance of early diagnosis of this tumor $[9,16]$. The other prognostic factors described in the literature are the quality of surgical excision and the degree of histological differentiation $[2,9,20]$.

Recurrences are observed in $77 \%$ of cases and after an average delay of 12.8 months [8], which was observed in our patient, a recurrence at 5 months of diagnosis.

Metastases are mainly by the hematogenous route while lymph node involvement is rare [20]. The most frequently invaded organs are the lung, contralateral breast and bone [17].

\section{CONCLUSION}

Radiation-induced breast angisarcoma represents a rare complication of radiotherapy in the context of breast cancer. This tumor has a poor prognosis and its diagnosis must be early because the tumor size on discovery constitutes the major prognostic factor. This diagnosis should be discussed before any change in skin color in a patient with a history of radiation therapy for breast cancer. The positive diagnosis is based on the histological analysis of biopsies performed at the level of the incriminated lesion. The treatment is essentially surgical and consists of a mammectomy with wide margins of excision.

\section{REFERENCES}

1. Rashmi C, Michael SS, Mary F. Breast sarcoma: treatment. 2020. Consulté le 28/12/2019.

2. Bobin Y, Dolbeau B, Bernard C, Mignotte H, Rivoire $\mathrm{M}$, Zlatof P. Angiosarcome du sein : à propos de quatre cas avec revue dela littérature. Bull Cancer. 1991;78:1037-44

3. Chen KT, Kirkegaard DD, Bocian JJ. Angiosarcome pri-mitive du sein chez l'homme. Ann Pathol. 2005; 25(3). 
4. Chouhou L, Moussaoui DR, Khaled H, Fehri HS, Jalil A, Souadka A, Alaoui MT, Gueddari B. Breast angiosarcomas: three case reports. InAnnales de chirurgie $2003 \mathrm{Feb}$;128(1):43-48.

5. Legrand L, Rimareix F, Bonvalot S, Tomasic G, Le Péchoux C, Domont J, Boulet B. Angiosarcome primitif du sein: corrélation anatomo-radiologique. Imagerie de la Femme. 2011 Jun 1;21(2):63-7.

6. Body G, Sauvanent, Calais G. Angiosarcome cutané du sein après adénocarcinome mammaire opéré et irradié. J Gynecol Obstet Biol Reprod. 1987;16:479-83

7. Monroe AT, Feigenberg SJ, Mendenhall NP. Angiosarcoma after breastconserving therapy. Cancer. 2003;97:1832-40.

8. Cahan WG, Woodard HQ, Higinbotham NL. Sarcoma arising in irradiated bone: Report of eleven cases. Cancer. 1948;1:3-29.

9. Blanchard DK, Reynolds C, Grant CS. Radiationinduced breast sarcoma. Am J Surg. 2002;184:356.

10. Kirova Y, Vilcoq JR, Asselain B. Sarcomes radioinduits après cancer du sein : expérience de l'institut curie et revue de la littérature. Cancer Radiother. 2006;10:83-90.

11. Boufettal H, Noun M, Hermas S, Samouh N, Benayad S, Karkouri M, Zamiati S. Angiosarcome mammaire: à propos d'un cas. InAnnales de Pathologie 2013 Jun 1 (Vol. 33, No. 3, pp. 217220). Elsevier Masson.

12. Wafa Rekik Bouraoui, Aida Goucha, Jamel Ben Hassouna, Bouthein Debbabi, Asma Nasfi, Hatem Bouzaiène et al. Les angiosarcomes du sein: à propos de dix cas. Imagerie de la Femme. 2011; 21(1):21-27.

13. Barrenetxea G, Schneider J, Tánago JG, pérez C, Cenreno MM, Escudero R. Angiosarcoma of the breast and pregnancy a new therapeutic approche. Eur J Obstet Gynecol Reprod Biol. 1995;60(1):879.

14. Kirova Y, Vilcoq JR, Asselain B. Sarcomes radioinduits après cancer du sein : expérience de l'institut curie et revue de la littérature. Cancer Radiother. 2006; 10:83.

15. Gutman H, Pollock RE, Ross MI. Sarcoma of the breast: implications for extent of therapy. Surgery. 1994;116:505-9.

16. Denoël C, Foucras L, De Lafontan B. À propos d'un cas rare de sarcome radio-induit du sein. Ann Chir Plast Esthet 2003;48:36

17. Donnell RM, Rosen PP, Lieberman PH, Kaufman RJ, Kay S, Braun DW Jr. Angiosarcoma and other vascular tumor of the breast. Am J Surg Pathol. 1981 Oct;5(7):629-42.

18. Merino MJ, Breman M, Carter D. Angiosarcoma of the breast. Am J Surg Pathol. 1983 Jan; 7(1):5360.

19. Nakamura R, Nagashima T, Sakakibara M. Angiosarcoma arising in the breast following breast-conserving surgery with radiation for breast carcinoma. Breast Cancer. 2007;14:245-9.

20. Rosen PP, Kimmel M, Ernsberger D. Mammary angiosarcoma. The prognostic significance of tumor differentiation. Cancer. 1988;62: 2145-51.

21. Billings SD, Mc Kenny JK, Folpe AL. Cutaneous angiosarcoma following breast-conserving surgery and radiation. Am J Surg Pathol. 2004; 28:781-8. 